\title{
Aerodynamic Design of the Bleed Slot in a Hypersonic Quiet Nozzle
}

\author{
Ruiqu Li*, Junmou Shen*, Feng Ji \\ China Academy of Aerospace Aerodynamics, Beijing, China

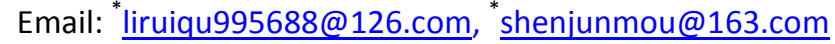

Received March 2014

\begin{abstract}
The bleed slot is necessary for the requirement of the hypersonic quiet flow all over the world. The aim of the bleed slot is to decrease the influence of the disturbances from the contraction of the quiet nozzle to the boundary layer downstream of the throat, so that the boundary layer of the nozzle could be maintained as laminar flow. The main parameters of the bleed slot include the distance from lip to throat (DLT) and the width of slot (WS). Various values of those parameters will affect the performance of the slot by changing the suction intensity of the bleed slot. Two kinds of the bleed slots in the world are compared in this paper and the aerodynamic design of the bleed slots is optimized based on the Purdue-type slot. The influences of the various values of those parameters to the flow field around the throat are analyzed and the optimizing results of DLT and WS are consistent with those relative data designed for the slot of the Boeing/AFOSR Ma 6 Quiet Tunnel.
\end{abstract}

Keywords

Hypersonic, Quiet Nozzle, Bleed Slot, Boundary Layer

\section{Introduction}

The earliest investigation on the bleed slot of the hypersonic quiet nozzle was pursued by Klebanoff et al. [1] in 1961. The aim is to maintain laminar flow along the walls and thus eliminate the source of the disturbances entirely. It was unfortunate that the efforts of Klebanoff et al. [2] is unsuccessful, whereas the concept of a lateral suction slot in the subsonic region upstream of the throat was inherited by subsequent researchers of the quiet tunnel, such as Kendall [3] [4], Beckwith [5], Anders [6], Beckwith et al. [7] [8], Schneider [9], Taskinoglu et al. [10], Aradag et al. [11].

In 2008, Schneider [12] summarized the development of hypersonic quiet tunnels and concluded that all successful hypersonic quiet tunnels have used bleed slots upstream of the throat to remove streamwise vorticity that may be generated in the contraction-wall boundary layer.

\section{Classification of the Bleed Slot}

Up to now, there are two types of the bleed slots. The Langley-type slot shown in Figure 1 was applied to the

${ }^{*}$ Corresponding authors. 

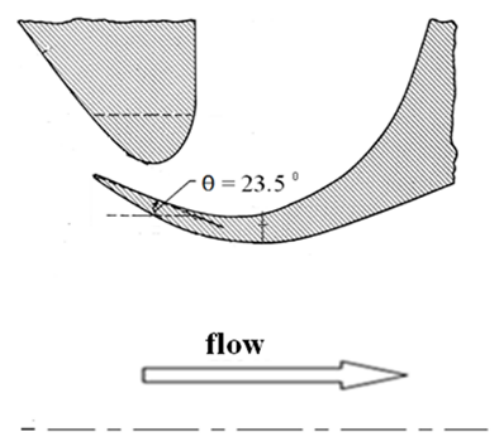

Figure 1. The scheme of the Langleytype bleed slot.

fabrication of NASA Langley's quiet tunnels [13] and Peking University's quiet tunnel [14]. And the Purduetype slot [15] shown in Figure 2 was used in the design of the BAM6QT.

The upper side and the lower side of the Langley-type slot are both curved surfaces and the angle between the upper edge of the lip and the nozzle axis is 23.5 degree. Compared with the Purdue-type slot with the lip's upper side of horizontal line, the Langley-type slot has more complex configuration, is injured by the free stream more easily and is more difficult to machining, install and maintain.

\section{Main Parameters of the Bleed Slot}

Geometrically, the bleed slot could be seen another nozzle which is similar with the quiet nozzle, thus the parameters shown in Figure 3 are satisfied with the following formula [16]:

$$
\left(r_{\text {entry }}^{2}-r_{\text {sep }}^{2}\right) /\left(r_{\text {slu }}^{2}-r_{\text {sll }}^{2}\right)=r_{\text {sep }}^{2} / r_{\text {throat }}^{2}
$$

where the radius of the upper wall at the bleed-lip tip is defined as "r_entry", the minimum width of the slot is defined as "min", with "r_slu" the radius to the upper side of the minimum and "r_sll" the radius to the lower side of the slot minimum. The radius to the separating-streamline stagnation point on the bleed-lip tip is "r_sep", and the radius of the main-flow throat is "r throat". Due to the similarity from the above equation, the main adjustable parameters are "min" (as the width of the slot) and " $\mathrm{x}$ sstep" (as the distance from the lip to the throat).

To avoid the separating region around the bleed lip, the bleed lip is usually suggested as the semi-elliptic or semispherical configuration. And the semispherical configuration used in this paper is the same as that of BAM6QT designed by Schneider.

\section{Optimization of the Parameters}

\subsection{Criterion of Optimization}

The function of the bleed slot is to remove the disturbances from the contraction and could be divided into strong, weak and moderate suction. The strong suction will induce the separation region at the outer wall of the slot to reduce the running time of the tunnel and the real free stream parameters such as unit Reynolds number. The weak suction will induce the separation region at the inner wall of the slot to bring new disturbances into the flow so that the aim of the bleed slot could not be satisfied. Thus, the values of "x_step" (DLT) and "min" (WS) are required to be carefully selected to adapt the intensity of suction to be moderate suction (Figure 4).

\subsection{Computation of Various Conditions}

Based on those two parameters of DLT and WS, the flow field of 23 suits of conditions shown in Table 1 will be calculated and analyzed.

Laminar AUSM model is used in the numerical calculation of the flow field. The wall is assumed as adiabatic and non slippage. The equations are solved by second-order upwind and coupling implicit scheme. The computational region of the flow field in the quiet nozzle is composed of 9 blocks with the height of first-level grid around the lip of $0.05 \mathrm{~mm}$ and with the stretching ratio of 1.1, and the local grids around the lip are shown in Figure 5. 

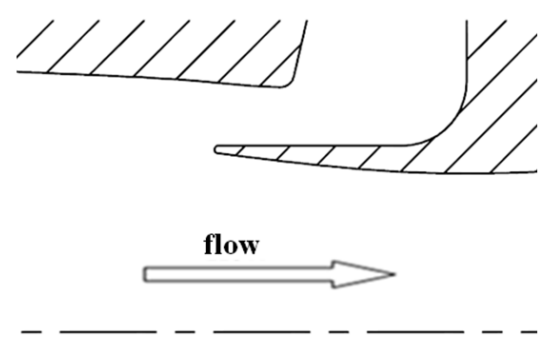

Figure 2. The scheme of the Purdue-type bleed slot.

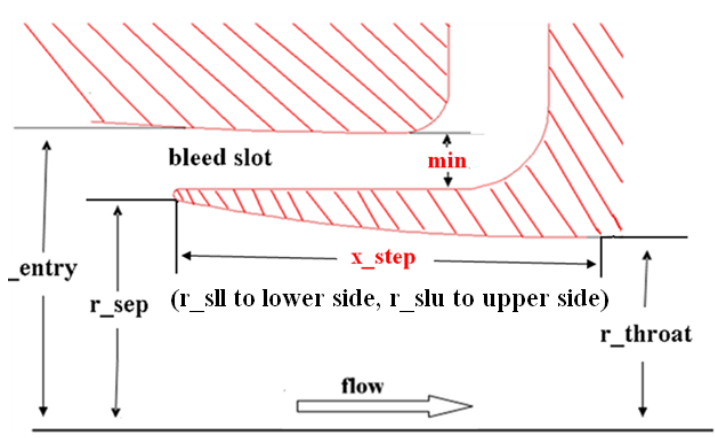

Figure 3. Geometry of the bleed slot and its parameters.
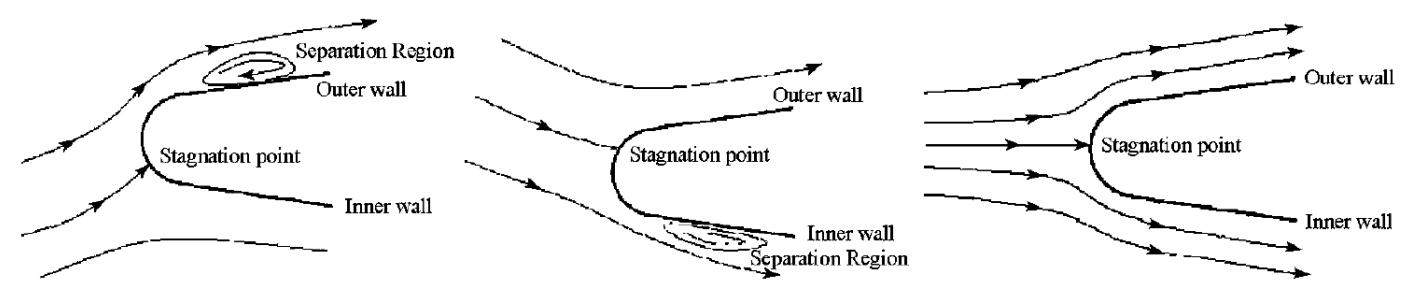

Figure 4. The influences of the suction intensity of the bleed slot to the flow field around the lip.

Table 1. Geometry parameters of the slot selected to calculate ( $\mathrm{mm})$.

\begin{tabular}{cccccccccc}
\hline \multirow{2}{*}{ case } & parameter & \multicolumn{7}{c}{ x_step } \\
\cline { 3 - 9 } & & 10 & 15 & 20 & 25 & 30 & 40 & 60 & 100 \\
\hline \multirow{3}{*}{1} & r_entry & 24.657 & 25.075 & 25.326 & 25.577 & 25.827 & 25.926 & 27.331 & 29.336 \\
& Min & 3.708 & 3.708 & 3.708 & 3.708 & 3.708 & 3.708 & 3.708 & 3.708 \\
& r_sep & 19.805 & 20.224 & 20.475 & 20.725 & 20.976 & 21.075 & 22.480 & 24.485 \\
& r_entry & 21.482 & -- & -- & 22.402 & -- & 22.751 & 24.256 & 26.161 \\
2 & Min & 0.731 & -- & -- & 0.731 & -- & 0.731 & 0.731 & 0.731 \\
& r_sep & 19.805 & -- & -- & 20.725 & -- & 21.075 & 22.480 & 24.485 \\
& r_entry & 22.422 & -- & -- & 23.342 & -- & 23.691 & 25.096 & 27.100 \\
3 & Min & 1.575 & -- & -- & 1.575 & -- & 1.575 & 1.575 & 1.575 \\
& r_sep & 19.805 & -- & -- & 20.725 & -- & 21.075 & 22.480 & 24.485 \\
& r_entry & 26.766 & -- & -- & 27.685 & -- & 28.034 & 29.440 & 31.444 \\
& Min & 5.817 & -- & -- & 5.817 & -- & 5.817 & 5.817 & 5.817 \\
& r_sep & 19.805 & -- & -- & 20.725 & -- & 21.075 & 22.480 & 24.485 \\
\hline
\end{tabular}




\subsection{Optimization of DLT}

The Mach number contours around the bleed slot at various DLT from $10 \mathrm{~mm}$ to $100 \mathrm{~mm}$ are shown in Figures 6(a)-(h). The width of the slot is $3.708 \mathrm{~mm}$. When the value of " $\mathrm{x}$ sstep" is smaller, the stagnation point is over the central axial line of the lip and the intensity of suction is closer to weak suction. With the increase of the "x_step", the stagnation point will move down and the suction of the bleed slot will become stronger. When the "x_step" is from $20 \mathrm{~mm}$ to $40 \mathrm{~mm}$, the intensity of suction is mostly close to the moderate suction.

\subsection{Optimization of WS}

Four cases of various width of the slot are numerical calculated to analyze the influence of the width of the slot to the flow field around the lip. Figure 7 and Figure 8 show that the Mach number contours at the $x_{-}$step $=25$ $\mathrm{mm}$ and $40 \mathrm{~mm}$, and the results at $\mathrm{x}_{-}$step $=10 \mathrm{~mm}, 60 \mathrm{~mm}$ and $100 \mathrm{~mm}$ are also calculated but are not shown here.

The influence of various DLT and WS to the stagnation point is shown in Figure 9. Here, $\Delta y$ is defined as the radial distance from the leading edge of the lip to the stagnation point. When $\Delta y>0$, the intensity of suction is weak suction; $\Delta y<0$, it is strong suction and $\Delta y=0$ means moderate suction. Figure 9 shows that when the "x_step" is fixed, with the increase of the width of the slot, the stagnation point moves from the upper side to the lower side of the leading edge of the lip, and the intensity of suction is also stronger. So when the " $\mathrm{x}$ step" is selected as the region from $20 \mathrm{~mm}$ to $40 \mathrm{~mm}$ in previous chapter, the most appropriate value of "min" is $3 . \overline{7} 08 \mathrm{~mm}$.

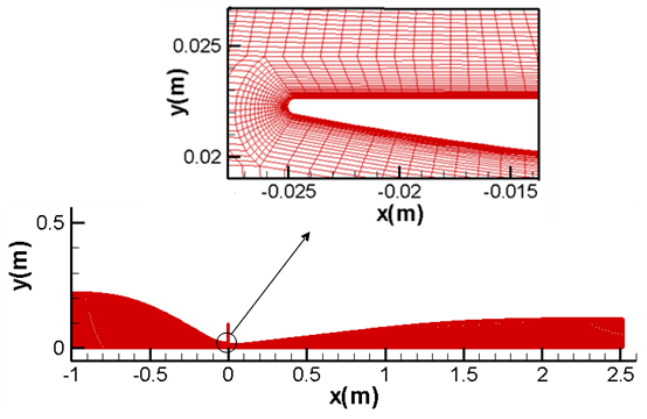

Figure 5. Grids in the nozzle.

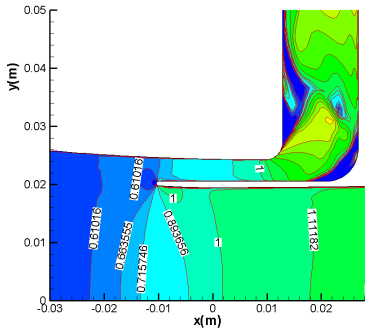

(a)

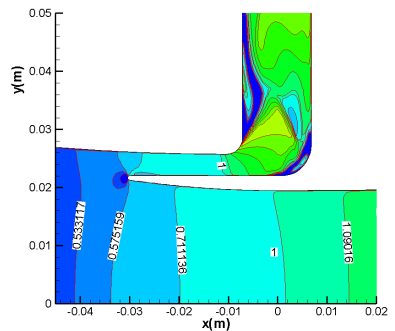

(e)

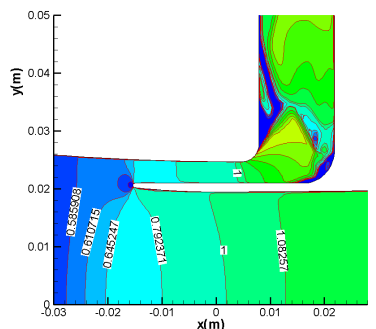

(b)

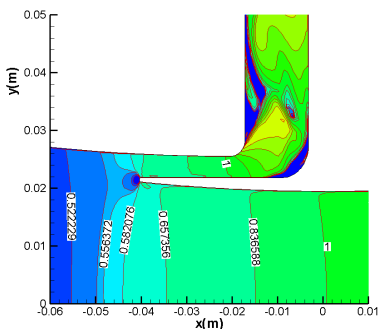

(f)

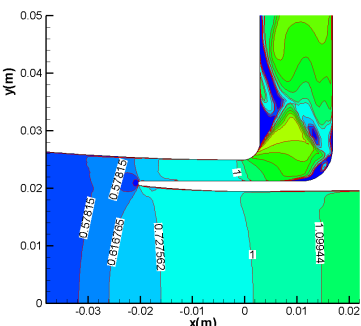

(c)

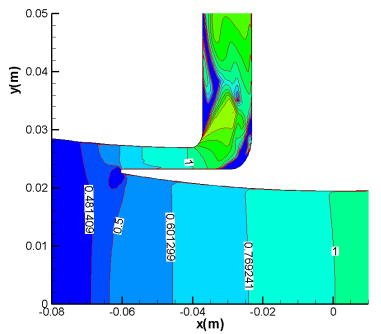

(g)

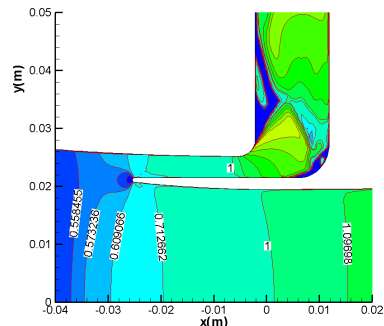

(d)

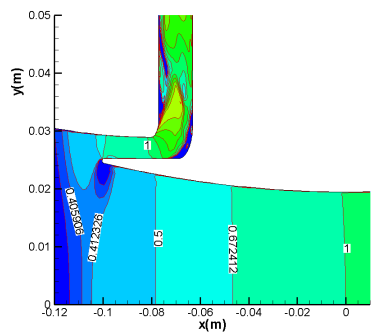

(h)

Figure 6. Mach number contours at various DLT when "min" = $3.708 \mathrm{~mm}$. (a) x_step = $10 \mathrm{~mm}$; (b) x_step = $15 \mathrm{~mm}$; (c) $\mathrm{x}$ _step $=20 \mathrm{~mm}$; (d) x_step $=25 \mathrm{~mm}$; (e) x_step $=30 \mathrm{~mm}$; (f) x_step $=40 \mathrm{~mm}$; (g) x_step $=60 \mathrm{~mm}$; (h) x_step $=100 \mathrm{~mm}$. 


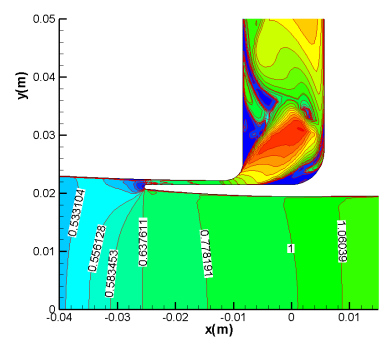

(a)

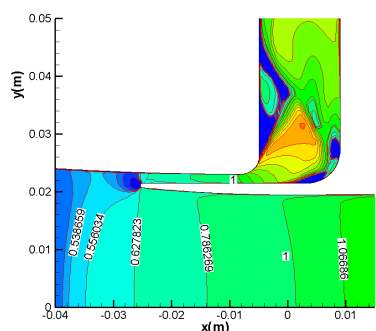

(b)

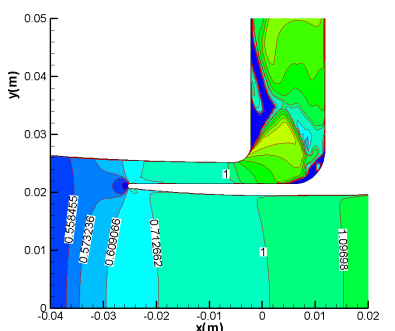

(c)

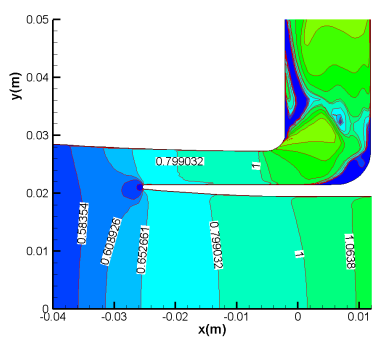

(d)

Figure 7. Mach number contours at various WS when "x_step" = $25 \mathrm{~mm}$. (a) $\min =0.731 \mathrm{~mm}$; (b) $\min =1.575 \mathrm{~mm}$; (c) $\min =3.708 \mathrm{~mm}$; (d) $\min =5.817 \mathrm{~mm}$.

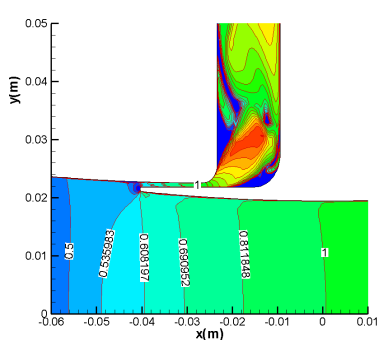

(a)

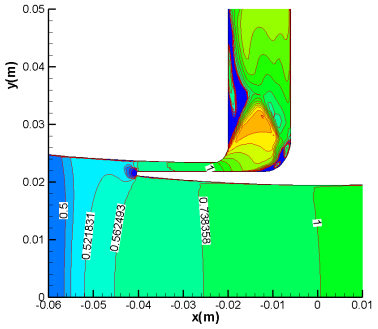

(b)

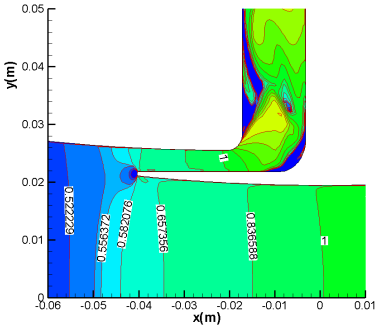

(c)

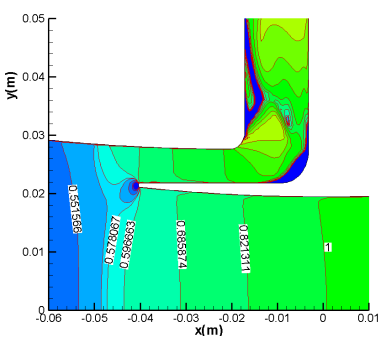

(d)

Figure 8. Mach number contours at various WS when "x_step" $=40 \mathrm{~mm}$. (a) $\min =0.731 \mathrm{~mm}$; (b) $\min =1.575 \mathrm{~mm}$; (c) $\min =3.708 \mathrm{~mm}$; (d) $\min =5.817 \mathrm{~mm}$.

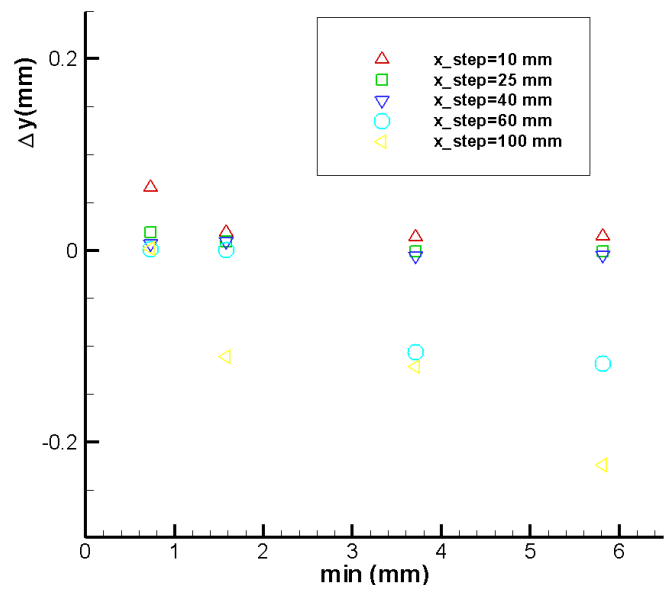

Figure 9. Influence of the various DLT and WS to the stagnation point.

\section{Concluding Remarks}

The requirement of the quiet-flow test region in the quiet tunnel is seriously relied on the control of the boundary layer on the nozzle wall by the use of the bleed slot settled in front of the throat. Two kinds of bleed slot are briefly introduced and compared each other. The Purdue-type bleed slot with simpler configuration is more suited for us to machining, install and maintain.

The main parameters of the bleed slot mainly include the distance from the lip to the throat (DLT) and the width of the slot (WS). A numerical analysis on the influence of those two parameters to the flow field around the lip of the Purdue-type slot is performed in this paper. The Mach number contours maps show that the stagnation point will be changed with those two parameters. When WS is fixed, with the increase of DLT, the intensity of suction becomes stronger, and when DLT is fixed, with the increase of WS, the intensity of suction also becomes stronger. The optimal value of DLT is from $20 \mathrm{~mm}$ to $40 \mathrm{~mm}$, and the corresponding value of WS is $3.708 \mathrm{~mm}$. 


\section{References}

[1] Klebanoff, P.S., Spangenberg, W. and Schubauer, G.B. (1961) Investigation of Boundary Layer Transition. Progress Report of National Bureau of Standards, Available from NASA STI as 62N10625.

[2] Klebanoff, P.S. and Spangenberg, W. (1965) Investigation of Boundary Layer Transition. Progress Report of National Bureau of Standards, Available from NASA STI as 65N89192, NASA-CR-67495.

[3] Kendall Jr., J.M. (1967) Supersonic Boundary Layer Stability Experiments. In: McCauley, W.D. Ed., Boundary Layer Transition Study Group Meeting, Vol. II, Session on Boundary Layer Stability, Aerospace Corp., San Bernardino; also Air Force Rept. BSD-TR-67-213, Vol. 2.

[4] Kendall Jr., J.M. (1974) Wind Tunnel Experiments Relating to Supersonic and Hypersonic Boundary-Layer Transition. AIAA Paper: 1974-0133.

[5] Beckwith, I.E. (1975) Development of a High Reynolds Number Quiet Tunnel for Transition Research. AIAA Journal, 13, 300-306. http://dx.doi.org/10.2514/3.49695

[6] Anders, J.B., Stainback, P.C., Keefe, L.R. and Beckwith, I.E. (1977) Fluctuating Disturbances in a Mach-5 Wind Tunnel. AIAA Journal, 15, 1123-1129. http://dx.doi.org/10.2514/3.60763

[7] Beckwith, I.E., Creel, T., Chen, F. and Kendall, J. (1983) Freestream Noise and Transition Measurements on a Cone in a Mach-3.5 Pilot Low-Disturbance Tunnel. NASA-TP-2180.

[8] Beckwith, I.E., Chen, F.J. and Malik, M.R. (1988) Design and Fabrication Requirements for Low-Noise Supersonic/Hypersonic Wind Tunnels. AIAA Paper: 1988-0143.

[9] Schneider, S.P. (1998) Design and Fabrication of a 9-Inch Mach-6 Quiet-Flow Ludwieg Tube. AIAA Paper: 19982511.

[10] Taskinoglu, E.S., Knight, D.D. and Schneider, S.P. (2006) Computational Fluid Dynamics Evaluation of Bleed Slot of the Purdue Mach 6 Quiet Tunnel. AIAA Journal, 44, 1360-1362. http://dx.doi.org/10.2514/1.17231

[11] Aradag, S., Knight, D.D. and Schneider, S.P. (2006) Bleed Lip Geometry Effects on the Flow in a Hypersonic Wind Tunnel. AIAA Journal, 44, 2133-2136. http://dx.doi.org/10.2514/1.23064

[12] Schneider, S.P. (2008) Development of Hypersonic Quiet Tunnels. Journal of Spacecraft and Rockets, 45, $641-664$. http://dx.doi.org/10.2514/1.34489

[13] Beckwith, I.E. and Holley, B.B. (1981) Görtler Vortices and Transition in Wall Boundary Layers of Two Mach-5 Nozzles. NASA-TP-1869.

[14] Zhou, Y.W., Yi, S.H., Chen, Z., Lu, X.G. and Ge, Y. (2011) The Aerodynamic and Structural Research of Mach 6 Hypersonic Quiet Wind Tunnel. Journal of National University of Defense Technology, 33, 14-17.

[15] Schneider, S.P., Matsumura, S., Rufer, S., Skoch, C. and Swanson, E. (2002) Progress in the Operation of the Boeing/AFOSR Mach-6 Quiet Tunnel. AIAA Paper: 2002-3033.

[16] Schneider, S.P., Matsumura, S., Rufer, S., Skock, C. and Swanson, E. (2003) Hypersonic Stability and Transition Experiments on Blunt Cones and a Generic Scramjet Forebody. AIAA Paper: 2003-1130. 